\title{
LA LEY DEL PERSEGUIDOR: UNA INTRODUCCIÓN AL TERRORISMO RELIGIOSO JUDÍO
}

\author{
The law of the prosecutor: \\ An introduction to Jewish religious terrorism
}

Víctor Manuel Amado Castro

Universidad del País Vasco / Euskal Herriko Unibertstatea victor.amado@ehu.es

Cómo citar este artículo/Citation:

Víctor Manuel AMADO CASTRO (2018), "La ley del perseguidor: Una introducción al terrorismo religioso judío", Hispania Nova, 16, págs. 417-444, DOI: https://doi.org/10.20318/hn.2018.4043
Copyright: () HISPANIA NOVA es una revista debidamente registrada, con ISSN I I38-7319 y Depósito Legal M 9472-1998. Los textos publicados en esta revista están -si no se indica lo contrario- bajo una licencia Reconocimiento-Sin obras derivadas 3.0 España de Creative Commons. Puede copiarlos, distribuirlos y comunicarlos públicamente siempre que cite su autor y la revista y la institución que los publica y no haga con ellos obras derivadas. La licencia completa se puede consultar en: http://creativecommons.org/licenses/by-nd/3.0/es/deed.es
Resumen: Este artículo aborda a modo de introducción una historia del terrorismo religioso judío desde el nacimiento del Estado de Israel hasta nuestros días. Centrándose exclusivamente en este fenómeno, enumera y describe cronológicamente los diferentes grupos terroristas religiosos judíos que han actuado en Israel, cada uno en un contexto determinado. Desde el primer grupo autodenominado Brit Hakanaim (pacto de los Zelotes) hasta Bat Ayin, este fenómeno ha causado varias víctimas -menos en comparación con el terrorismo árabe- la mayoría de ellas palestinos y árabes israelíes, aunque también ha habido víctimas entre la población judía israelí. Este texto apunta al denominado mesianismo político como sustrato ideológico y la base intelectual de este fenómeno. Se describe de manera somera algunas de las medidas que el Estado de Israel ha tomado para combatir este terrorismo autóctono. Como conclusión se hace una radiografía del terrorismo religioso judío en comparación con otros fenómenos análogos.

Palabras clave: Israel, terrorismo, terrorismo judío, terrorismo religioso, mesianismo.

\begin{abstract}
This article approaches, as an introduction, a history of Jewish religious terrorism from the birth of the State of Israel to the present day. Focusing exclusively on this phenomenon, it lists and describes chronologically the different Jewish religious terrorist groups that have acted in Israel, each in a given context. From the first group called the Brit Hakanaim to Bat Ayin, this phenomenon has caused a number of victims - far fewer than Arab terrorism - most of them Palestinians and Israeli Arabs, although there have also been casualties among the Israeli Jewish population. The current paper states the so-called political messianic as the ideological substrate and the intellectual basis of this phenomenon. It briefly describes some of the measures that the State of Israel has taken to combat this autochthonous terrorism. As a conclusion, a picture of Jewish religious terrorism is made, in comparison with other similar phenomena.
\end{abstract}

Keywords: Israel, terrorism, Jewish terrorism, religious terrorism, messianic. 


\section{$\underline{\text { I. Introducción }}^{1}$}

A día de hoy no existe una definición universal de terrorismo aprobada por la Asamblea General de las Naciones Unidas, y desde el año 1972 el Comité Especial sobre el Terrorismo de la Sexta Comisión de este organismo ha tratado sin éxito de lograrla. Fue a partir del 2001, tras los atentados terroristas llevados a cabo en suelo norteamericano cuando se creó el denominado Comité Contra el Terrorismo ${ }^{2}$ a partir de la resolución 1373 (2001) aprobada por el Consejo de Seguridad de las Naciones Unidas $^{3}$. Entre los objetivos fundacionales de este organismo estaba el intentar llegar a un acuerdo para una definición universal de terrorismo. $Y$ fue precisamente en ese contexto en el que el Consejo de Seguridad de Naciones Unidas en su resolución 1566 (2004) propuso una definición que, al no haber sido aprobada por el plenario de la ONU, no se convirtió en vinculante y por lo tanto no es aplicable en el ámbito del derecho internacional ${ }^{4}$. Ante la falta de una declaración universal ha sido el marco legal

\footnotetext{
${ }^{1}$ La elaboración de este artículo ha sido posible gracias a la financiación de los siguientes dos proyectos de investigación: Grupo acreditado Tipo A del Sistema Universitario Vasco IT-708-13, Historia Política y Social del País Vasco Contemporáneo; y proyecto Violencia política, memoria e identidad territorial. El peso de las percepciones del pasado en la política vasca HAR2014-51956-P. Ministerio de Economía y Competitividad (MINECO).

${ }^{2}$ Recuperado de http://www.un.org/es/sc/ctc/aboutus.html (consulta: 23 diciembre 2016).

${ }^{3}$ Consúltese dicha resolución sobre todo en su punto 6 en el que se "decide establecer, de conformidad con el artículo 28 de su reglamento provisional, un Comité del Consejo de Seguridad, integrado por todos los miembros del Consejo, para que verifique la aplicación de la presente resolución, con la asistencia de los expertos que se consideren apropiados, y exhorta a todos los Estados a que informen al Comité, a más tardar noventa días después de la fecha de aprobación de la presente resolución y más adelante conforme a un calendario que será propuesto por el Comité, de las medidas que hayan adoptado para aplicar la presente resolución". Recuperado de http://www.un.org/es/comun/docs/?symbol=S/RES/1373(2001) (consulta: 23 diciembre 2016).

${ }^{4}$ La definición dice lo siguiente: "Recuerda que los actos criminales, inclusive contra civiles, cometidos con la intención de causar la muerte o lesiones corporales graves o de tomar rehenes con el propósito de provocar un estado de terror en la población en general, en un grupo de personas o en determinada persona, intimidar a una población u obligar a un gobierno o a una organización internacional a realizar un acto, o a abstenerse de realizarlo, que constituyen delitos definidos en los convenios, las convenciones y los protocolos internacionales relativos al terrorismo y comprendidos en su ámbito, no admiten justificación en circunstancia alguna por consideraciones de índole política, filosófica, ideológica, racial, étnica, religiosa u otra similar, e Insta a todos los Estados a prevenirlos y, si ocurren, a
} 
de cada país el que ha delimitado mediante su legislación las acciones que caben ser interpretadas como terrorismo.

El presente texto aborda solo el fenómeno del terrorismo religioso judío. Quedan excluidos por tanto otros fenómenos terroristas como los atentados llevados a cabo por organizaciones judías no religiosas -de raíz mayoritariamente sionista- contra la autoridad mandatoria británica y contra los árabes palestinos. En su mayor parte dichos actos fueron protagonizados por dos grupos paramilitares herederos de la corriente sionista revisionista de Zeev Jabostinsky: el Etzel y Lehi ${ }^{5}$. Entre 1939 y 1942 , el primero de estos grupos llevó a cabo 60 ataques terroristas, matando a más de 120 palestinos y mutilando a unos varios cientos más. Por su parte, los miembros de Lehi asesinaron el 6 de noviembre de 1944 a Lord Moyne, Ministro residente en Oriente Medio que vivía en El Cairo. Pero sin duda uno de los atentados que mayor repercusión tuvo fue el perpetrado el 26 de julio de 1946, cuando una potentísima carga de explosivos activada por agentes de Etzel derribó por completo el hotel King David en Jerusalén. La bomba que explotó en este edificio, sede administrativa de la autoridad mandatoria británica, costó la vida a 91 británicos e hirió a cerca de 500 personas. La última operación terrorista de Lehi se produjo el 17 de septiembre de 1948 y terminó con la vida del conde sueco Folke Bernadotte que, como mediador de la ONU, había propuesto un plan que alteraba significativamente los términos de la resolución de partición de Palestina aprobada por la Asamblea de Naciones Unidas en noviembre de 1947.

También quedan fuera de este texto aquellos hechos susceptibles de ser denominados como actos terroristas llevados a cabo por las instituciones estatales israelíes, tanto militares como civiles. Por último, estarían fuera de esta reflexión las actuaciones de fuerzas militares o de seguridad israelíes contra dirigentes palestinos acusados de terrorismo en los territorios ocupados, y que en ámbitos diplomáticos se definieron como "ejecuciones extrajudiciales". Todos estos casos quedan fuera de este artículo, no por su hipotética dificultad para definirlos, sino porque en ningún caso tienen origen religioso.

cerciorarse de que sean sancionados con penas compatibles con su grave naturaleza". Resolución 1566 (2004) aprobada por el Consejo de Seguridad en su 5053ª sesión, celebrada el 8 de octubre de 2004.

${ }^{5}$ Sobre los escritos de Jabotinsky consúltese http://en.jabotinsky.org/ (consulta: 23 diciembre 2016). 


\section{Marco teórico y estado de la cuestión}

Tal y como apunta González Calleja ${ }^{6}$, la relación entre religión y terrorismo tiene más de dos mil años de antigüedad. Se puede afirmar que hasta el siglo XIX la justificación casi única para cualquier acto de este tipo de violencia era la religión ${ }^{7}$. Con la llegada del siglo XX fueron las nuevas ideologías, como el nacionalismo, el marxismo, el anarquismo o el nihilismo, las que conformaron la base ideológica de la violencia política; es decir, se produjo una secularización del terrorismo. A partir de la segunda posguerra mundial fueron los movimientos de carácter anticolonial y de liberación nacional los que utilizaron el terrorismo para conseguir sus objetivos. Es en esta tipología de violencia política, o en la denominada tercera oleada terrorista (González Calleja, 2013), en la que habría que interpretar a los grupos terroristas sionistas como Irún o Lehi. Siguiendo con la propuesta de oleadas terroristas, el fenómeno violento de inspiración religiosa reapareció en el último cuarto del siglo XX con un afán de destrucción indiscriminada, evolucionando hacia una amplitud global en su campo de actuación, especialmente con la aparición de fenómenos como Al Qaeda y el ISIS, autodenominado Estado Islámico de Irak y Levante.

A la hora de caracterizar el fenómeno terrorista de base religiosa, Walter Laqueur $^{8}$ ubica el auge de este fanatismo religioso en un proceso paralelo al del fracaso de las ideologías revolucionarias, marxistas y nacionalistas. Para este autor, la actuación violenta que ejercen estos grupos habría que enmarcarla en la interpretación que sus miembros hacen de la inevitabilidad de una batalla final entre el Bien y el Mal, en el que ha de producirse la destrucción de las actuales sociedades corruptas. Por lo tanto, el objetivo de este tipo de terrorismos tendría como fin cumplir un mandato divino, imponiendo una visión única, en este caso religiosa, de los modos de vida. Ese carácter mesiánico y trascendente del terrorismo religioso explicaría la utilización por su parte de distintas tipologías de violencia: entre otras el denominado "martirio" o "sacrificio" como medio de alcanzar un supuesto paraíso. En suma, la aparición del

\footnotetext{
${ }^{6}$ Eduardo GONZÁLEZ CALLEJA., El laboratorio del miedo: Una historia general del terrorismo, de los sicarios a Al Qa'ida, Barcelona, Crítica 2013.

7 David RAPAPORT, "Fear and Trembling: Terrorism in three Religious Traditions", The American Political Science Review, vol. LXX-VIII, septiembre, pp. 658-677, 1984.

${ }^{8}$ Walter LAQUEUR, La guerra sin fin. El terrorismo en el siglo XXI, Destino, Barcelona 2003.
} 
terrorista suicida. Según Juergensmeyer ${ }^{9}$ los grupos terroristas de base religiosa están caracterizados por tres factores: rechazo de los valores liberales laicos tanto públicos como privados; derivado de lo anterior, negativa a diferenciar entre la esfera pública y la privada, espacio este último donde las sociedades laicizadas ubican la práctica religiosa; y, por último, la sustitución de los valores de la modernidad por los principios tradicionales.

Además, en este tipo de grupos es muy importante la figura del líder, que se suele autodenominar profeta, y que ejercería de mediador entre la divinidad y los hombres: Meir Kahan, Hequ Yasin, Bin Laden o Al Baghadi son ejemplos de ello. Por último, estos movimientos tienden también a caracterizarse por tener un fuerte componente comunitarista, que alimenta la precepción que tienen sus componentes de ser atacados por el resto de la sociedad. Debido a esa percepción, estos grupos suelen articular un discurso de carácter apocalíptico que imposibilita, en la mayoría de las ocasiones, la negociación en el terreno de lo político. Por último, cabe resaltar que en la literatura israelí no abundan las monografías sobre el terrorismo judío en general, y tampoco sobre el religioso en particular. No obstante, y con las limitaciones anteriormente señaladas, se debe destacar en este ámbito del estudio del terrorismo judío de raíz religiosa la obra de Ami Pedahzur y Arie Perliger Jewish Terrorism in Israel (Columbia University Press, 2011), así como los trabajos de Noemi Gal-Or ${ }^{10}$ y Ehud Sprinzak ${ }^{11}$.

\footnotetext{
${ }^{9}$ Mark JUERGENSMEYER, Terror in the Mind of God, The Global Rise of Religious Violence, University of California Press (4 ${ }^{\text {th }}$ edition), 2017.

${ }^{10}$ Cabe resaltar entre otros trabajos de esta autora: The Jewish Underground: Our Terrorism, Tel Aviv, Hakibbutz Hameuchad, Kav Adom Series, 1990; "Israeli-Jewish Terrorism and the Crisis of Israeli Democracy", Gesher, No. 2/113, 1986; "The Role of Extremist Political Groups in the Context of PoliticalSecurity Relations between Israel and Palestinians", Confidence Building Measures in the Middle East, Gabriel BEN-DOR and David B. DEWITT (eds.), Boulder, Co., Westview Press, 1994. Más información en su página web, http://www.kpu.ca/arts/political-science/faculty/noemi-gal-or (consulta: 23 diciembre 2016).

${ }^{11}$ De este autor cabe mencionar: "From messianic pioneering to vigilante terrorism: The case of the gush emunim underground" Journal of Strategic Studies, junio 2008 y "Kach and Meir Kahane: The Emergence of Jewish Quasi-Fascism I: Origins and Development" Patterns of Prejudice online, mayo 2010 y "Kach and Meir Kahane: The emergence of Jewish quasi-fascism II: Ideology and politics" Patterns of Prejudic, online , mayo 2010.
} 


\section{Una perspectiva histórica del terrorismo religioso judío.}

Tal y como apunta Noemi Gal-Or la incidencia del terrorismo religioso judío en Israel ha sido mucho menor que la del terrorismo árabe, pero cabe resaltar que la motivación de los actos terroristas judíos cambió de manera radical tras la constitución del Estado de Israel el 14 de mayo de 1948. Fue sobre todo a partir de la década de los cincuenta cuando el factor religioso adquirió un mayor protagonismo en dichos actos. Así, la primera referencia que se tiene en el nuevo Estado de Israel de terrorismo religioso judío fueron los atentados perpetrados por el grupo Brit Hakanaim (Pacto de los Zelotes). El objetivo de este grupo nacido en Jerusalén en abril de 1950 y que estuvo compuesto por estudiantes de la Yeshiva (escuelas religiosas judías) de "Porat Yosef" fue el de luchar contra lo que ellos entendían como una creciente secularización del pueblo judío, por una parte, y contra la, en su opinión, creciente marginación de la comunidad ultraortodoxa judía. Se estima que no más de 35 personas, la mayoría de ellos estudiantes de la Torá, conformaron este grupo, entre ellos hay que destacar al que fuera su cabecilla, Mordechai Eliyahu, quien llegó a ser rabino jefe de los sefardíes de Israel de 1983 a 1993, o al rabino Shlomo Lorinzc miembro del parlamento de Israel desde 1951 hasta 1986. La actividad violenta de este grupo se inició tras la decisión del gobierno de Israel de que los nuevos inmigrantes u olim que llegaran a Israel, entre ellos los hijos de los ultraortodoxos, también tenían que integrarse en el sistema educativo nacional de carácter secular, a lo que estos se oponían. Así, la aparición de este grupo terrorista hay que interpretarla en un contexto de creciente tensión en el seno de la sociedad israelí entre los sectores ultrareligiosos y el resto que apostaba mayoritariamente por un Estado secular.

El primer acto violento de Brit Hakanaim se produjo el 18 de enero 1951. Ese día prendieron fuego a varios coches particulares en Jerusalén bajo la acusación de que sus dueños los conducían en sabbat ${ }^{12}$. Entre los meses de febrero y marzo de ese mismo año varios coches corrieron la misma suerte, mientras que un restaurante de la ciudad santa sufrió un atentado con una bomba acusado también de abrir en sábado. Pero sin duda la acción más "audaz" que este grupo intentó perpetrar fue la de un

\footnotetext{
${ }^{12}$ Las referencias de los atentados terroristas que voy a mencionar en este artículo se pueden cotejar en el trabajo de Ami PEDAHZUR y Arie PERLIGER, Jewish Terrorism in Israel. Columbia University Press, 2011.
} 
doble atentado. De una parte hacer estallar una bomba en la sede del parlamento israelí el día en el que se celebraba la sesión en la que se iba a aprobar la participación de las mujeres en el ejército, y por otra quemar los archivos de la oficina de reclutamiento del Ministerio de Defensa de Israel. Finalmente, este acto se quedó en una amenaza de bomba, pues antes de llevarlo a cabo los integrantes de este grupo fueron detenidos por los servicios de seguridad interior de Israel conocidos como Shin $\mathrm{Bet}^{13}$. La mayor parte de sus integrantes fueron puestos en libertad y tan solo cuatro de ellos, sus cabecillas, fueron condenados a penas que oscilaron entre los seis meses y el año de cárcel ${ }^{14}$. Tal y como apuntan Pedahzur y Perliger (2011), estos actos terroristas fueron entendidos por el conjunto de la sociedad israelí, y especialmente por el gobierno de Ben Gurion, como una mal menor y una consecuencia inevitable del nacimiento y puesta en marcha del nuevo Estado.

\subsection{Camp David o el renacer del terrorismo judío}

Tras casi un cuarto de siglo en calma el terrorismo judío volvió a actuar al inicio de los años ochenta del siglo XX. Pero a diferencia de los anteriores, los objetivos de estos actos terroristas se centraron casi exclusivamente en la población palestina. EI rebrote del fenómeno terrorista en Israel se produjo en el contexto histórico posterior a la guerra del Yom Kippur de 1973 y de los acuerdos de Camp David de 1978, que supusieron la paz con Egipto. A nivel general, cabe resaltar que esta reaparición del terrorismo religioso judío se dio cuando el Estado de Israel empezó a ser gobernado desde 1977 por la derecha sionista del Likud, partido político heredero del sionismo revisionista de Jabostinsky. Es más, el líder de esta formación que se convirtió en Primer Ministro, Menachem Begin, era antiguo cabecilla del Irgún, calificado como grupo terrorista por las autoridades británicas ${ }^{15}$.

\footnotetext{
${ }^{13}$ Sobre el papel de los servicios de seguridad interior israelíes en la lucha contra este tipo de terrorismo léase Ami PEDAHZUR: The Israeli Secret Services and the Struggle Against Terrorism. Columbia University Press, 2009.

${ }^{14}$ Yehuda Rieder, Mordechatri Eliyahu, Noah Wemesser y Eliyahu Raful-Rafael fueron los dirigentes Brit Hakanaim encarcelados.

${ }^{15}$ Sobre la biografía de Mencahem Begin léase: Menachem BEGIN. La rebelión. La lucha clandestina por la independencia de Israel. Inédita editores. Barcelona 2008.
} 
El primero de estos grupos fue el conocido como Jewish Underground ${ }^{16}$, escisión del movimiento representante del denominado mesianismo político Gush Emunim $^{17}$. Este grupo quería evitar a toda costa que se aplicara el principio de paz por territorios en los distintos acuerdos de paz que Israel firmara con los países árabes, como había sido el caso de Camp David, en los que el gobierno de Begin devolvió el Sinaí a Egipto y evacuó las colonias judías de aquella zona ${ }^{18}$. Así, y compuesto por antiguos miembros del Gush Emunim (Bloque de los Fieles), lo que este grupo perseguía con sus atentados eran básicamente tres objetivos: boicotear los acuerdos de paz con los estados árabes, detener la evacuación de los asentamientos judíos en el Sinaí y disuadir a los palestinos de sus ataques contra colonos judíos en los territorios ocupados. Para los dirigentes de este grupo terrorista la guerra de 1967, con la recuperación de los santos lugares, había supuesto el inicio del principio de la redención del pueblo judío. Por tanto la ocupación de los territorios del Israel bíblico con población judía era la manera de "redimir" la tierra del pueblo de Abraham. Desde esta premisa, la devolución del Sinaí por parte del Begin supuso una violación flagrante de este principio. Así, este grupo terrorista fue el primero en unir en su corpus ideológico los dos elementos básicos del mesianismo político: la territorialidad y el carácter sagrado y redencionista de la ocupación por judíos de la tierra de Israel. En cuanto a los miembros de Jewish Underground la mayoría de ellos se habían conocido en ámbitos comunes de sociabilidad como las yeshivas, e incluso algunos de ellos habían formado parte de unidades especiales de las Fuerzas de Defensa de Israel. En cualquier caso, y aun siendo un grupo terrorista, tanto sus actuaciones, que se produjeron durante cortos periodos de tiempo, como su carácter de camarilla, les

\footnotetext{
${ }^{16}$ El nombre de este grupo terrorista era Jewish Underground Emunim. Sobre este fenómeno consúltese Noemi GAL-OR: The Jewish Underground: Innovation or Recurrence? Tel Aviv, International Centre for Peace in the Middle East, 1986. NOTA DEL AUTOR: aunque el nombre de este grupo en hebreo es HaMakhteret HaYehudit, en este texto se utiliza su acepción en inglés porque es el que habitualmente aparece en la literatura al respecto.

17 Sobre el mesianismo político léase Víctor Manuel AMADO CASTRO: "Redimir la tierra: Origen, desarrollo e influencia del mesianismo político en Israel" Félix LUENGO TEIXIDOR y

Fernando MOLINA APARICIO (Editores) Los caminos de la nación. Factores de nacionalización en la sociedad española contemporánea. Granada, Comares, 2016.

18 Consúltese este tratado en: Israel Ministry of Foreign Affairs. Camp David Accords. September,17,1978. Recuperado de http://mfa.gov.il/MFA/ForeignPolicy/Peace/Guide/Pages/Camp\%20David\%20Accords.aspx (consulta: 23 diciembre 2016).
} 
hicieron carecer de una estructura jerárquica, sólida e institucionalizada que hiciera que este grupo se perpetuara en el tiempo.

En lo que hace referencia a su actividad violenta, esta se desarrolló entre 1980 y 1984, periodo en el que llevó a cabo una serie de ataques contra objetivos palestinos alrededor de Jerusalén y en toda la ribera occidental del rio Jordán. Los atentados más relevantes de Jewish Underground en sus inicios fueron la activación de coches bomba contra los alcaldes de Ramallah, Nablus, El-Bira, Belén y Hebrón en junio de 1980. Al mismo tiempo, los servicios de seguridad interior israelíes descubrieron que entre sus planes también tenían la intención de volar mediante explosivos la Cúpula de la Roca, en la mezquita de al-Aqsa, tercer lugar de peregrinación para el islam tras la Meca y Medina. Recuérdese que el monte del templo es también un lugar sagrado para el judaísmo ${ }^{19}$.

Pero el acto terrorista más sanguinario llevado a cabo por este grupo fue sin duda el ataque que perpetraron el 26 de julio de 1983 contra el Colegio Islámico en Hebrón, en el que tres estudiantes fueron asesinados y treinta tres heridos ${ }^{20}$. Se planificó con minuciosidad por parte de Jewish Underground y según la policía israelí los militantes que lo ejecutaron no tenían ninguna conexión con los que habían cometido los actos terroristas contra los alcaldes de las ciudades palestinas anteriormente mencionados. También se les atribuye los intentos frustrados de detonar explosivos en los autobuses de la East Jerusalem Transportation Company el 26 de abril de 1984. Tras este intento fallido los integrantes de este grupo fueron detenidos y se dio por concluida su actividad.

\footnotetext{
${ }^{19}$ Este lugar es comúnmente conocido para los no judíos como explanada de las mezquitas de Jerusalén.

${ }^{20}$ Consúltese esta noticia "Cuatro enmascarados causan la muerte a tres estudiantes palestinos en un tiroteo en la universidad de Hebrón" EL PAIS, 27/07/1983. Recuperado de http://elpais.com/diario/1983/07/27/internacional/428104806 850215.html o Corresponsales "Un grupo de encapuchados asalta y provoca el terror en la Universidad Árabe de Hebrón" en La Vanguardia pag 13, 27/07/1983. Recuperado de http://hemeroteca.lavanguardia.com/preview/1983/07/31/pagina13/32971249/pdf.html?search=hebron,

Richard BERNSTEIN "3 slain as gunmen attack Hebron Islamic college" New York Times 27/07/1983. Recuperado de http://www.nytimes.com/1983/07/27/world/3-slain-as-gunmen-attack-hebron-islamiccollege.html (consultas: 23 diciembre 2016).
} 


\subsubsection{El movimiento Kach}

Además de Jewish Underground actuó otro grupo terrorista con el nombre de Kach y dirigido por el rabino Meir Kahane. Este movimiento se articuló a través de una red de células que desarrolló una relativamente corta pero intensa actividad terrorista en Israel y en los territorios palestinos. El mentor y fundador de este grupo fue el rabino Meir Kahane, que nació en los Estados Unidos en 1930, y cuyo padre perteneció al movimiento del sionismo revisionista liderado por Zeev Jabotinsky, del que además fue amigo personal. En su adolescencia Meir Kahane perteneció a las juventudes de este movimiento revisionista conocidas como Betar, graduándose más tarde en Derecho Internacional por la Universidad de Nueva York, y siendo posteriormente ordenado rabino en la yeshiva de Mir.

Kahane fue primeramente editor del periódico Jewish Press ${ }^{21}$, tarea que compaginó con su labor religiosa como rabino. Pero su militancia política más reseñable comenzó en 1968 cuando fundó la Jewish Defense League, cuyas acciones en aquel tiempo tenían como objetivo boicotear las actividades soviéticas en Nueva York como protesta -autodefensa según este líder- por el trato que el gobierno de Moscú daba a los judíos que vivían en la URSS. Esos actos le llevaron a la cárcel en Estados Unidos acusado de conspiración y de fabricación de bombas. Tras quedar en libertad en 1971 él y su familia se trasladaron a Israel donde fundó el partido $K{ }^{22}{ }^{22}$, un movimiento antiárabe que reivindicaba la anexión a Israel de todos los territorios ocupados, y la expulsión forzosa de todos los palestinos y ciudadanos árabes israelíes del país. Kahane reivindicó siempre su idea de que los objetivos del auténtico sionismo debían conseguirse por vías violentas. Esta actitud le llevó a ser encarcelado varias veces también en Israel, y a convertirse en el primer judío acusado de sedición en el

\footnotetext{
${ }^{21}$ The Jewissh Press es el periódico semanal en lengua inglesa más importante entre la comunidad ortodoxa judía en los Estados Unidos. Fue fundado por el Rabino Sholom Klass (1916-2000) y el Sr. Raphael Schreiber (1885-1980), y a partir de 1960 empezó a tener periodicidad semanal. Tal y como apunta en su página web: "Durante más de cinco décadas, The Jewish Press ha defendido los valores y los ideales de la Torá desde una perspectiva centrista u ortodoxa moderna...". Al mismo tiempo, este semanario dice también en su presentación que ha sido el hogar de un elenco de escritores muy estimulantes, entre los que cita al rabino Meir Kahane. Desde 2011 tiene edición digital y sigue siendo un medio de información referente tanto para la comunidad ortodoxa y nacionalista judía en los Estados Unidos como en Israel. Consúltese su sitio web http://www.jewishpress.com/ (consulta: 23 diciembre 2016).

${ }^{22}$ Sobre este movimiento léanse en sus reediciones más recientes: Meir KAHANE, The Ideology of Kach. Paperback 2005 o The Story of the Jewish Defense League, 2008.
} 
país hebreo. Lejos de cesar en sus objetivos y tras presentarse dos veces a las elecciones, en 1976 y en 1980, fue en los comicios celebrados en 1984 cuando consiguió un escaño en el parlamento. El crecimiento de este partido político fue constante hasta 1988, ya que a partir de entonces los miembros de esta formación no pudieron presentarse a las elecciones porque el gobierno de coalición del Likud-Partido Laborista, modificó una de las Leyes Básicas que conforman el cuerpo constitucional israelí. Concretamente fue la denominada Ley de la Knesset, que a partir de ese momento impidió que cualquier candidato que "incitara al racismo" se pudiera presentar a las elecciones, ya que además se ubicaba al margen de la legalidad ${ }^{23}$. Dos años más tarde, en 1990, Meir Khahane que ya había regresado a los Estados Unidos, fue asesinado por un fundamentalista egipcio a quien se detuvo en 1995 al estar implicado también en el atentado del World Trade Center de febrero de $1993^{24}$. Lejos de desaparecer, y tras la muerte de su fundador, este movimiento siguió teniendo una gran influencia en el escenario político israelí de la mano de su hijo Binyamin Zev, que lideró el Kahane Chai (Kahane vive) durante varios años. Finalmente, esta organización también fue prohibida y decretada ilegal en Israel en 1994, tras ser señalada por los Estados Unidos como una organización terrorista ${ }^{25}$. A su vez, Benyamin Zev Kahane y su esposa fueron asesinados el 31 de diciembre de 2000 por extremistas palestinos de Cisjordania en plena intifada de al-Aqsa ${ }^{26}$.

${ }^{23}$ El punto 7.a de la denominada Basic Law: The Knesset en sus enmiendas 9, 35 y 39 prevé tres supuestos en los que una persona que cumpliera los demás requisitos legales no puede ser candidato. Estos son: La negación de la existencia de Israel como Estado democrático judío, la incitación al racismo y apoyar la lucha armada de un estado enemigo contra Israel o de una organización terrorista contra el Estado de Israel. Léase el texto completo en http://knesset.gov.il/laws/special/eng/BasicLawTheKnesset.pdf (consulta: 23 diciembre 2016).

\footnotetext{
${ }^{24}$ Léase la obituario John KIFNER "Meir Kahane, 58, Israeli Militant and Founder of the Jewish Defense Leagueen" New York Times, 6/11/1990 http://www.nytimes.com/1990/11/06/obituaries/meir-kahane-58israeli-militant-and-founder-of-the-jewish-defense-league.html?pagewanted=all (consulta: 23 diciembre 2016).

${ }^{25}$ Desde que en su informe de 2006 el Departamento de Estado Norteamericano afirmara que esta organización había estado involucrada en distintos "low-levels attack" no se ha vuelto a reportar ninguna actividad de este grupo. Léase este informe en Country Reports on Terrorism 2006. United States Department of State Publication 11409 Office of the Coordinator for Counterterrorism April 2007, pag 257. En versión digital se puede consultar en http://www.state.gov/documents/organization/83383.pdf. Para informes posteriores incluido el del 2015 consúltese: http://www.state.gov/j/ct/index.htm (consulta: 23 diciembre 2016).

${ }^{26}$ Léase esta noticia Alan PHILPS "Extremist settler killed in Palestinian ambush" en Telegraph 1/01/2001 http://www.telegraph.co.uk/news/worldnews/middleeast/israel/1317827/Extremist-settler-killedin-Palestinian-ambush.html (consulta: 23 diciembre 2016).
} 
El movimiento kanista fue pionero en el surgimiento y en el fomento del terrorismo nacional-religioso judío. Sus miembros, en su mayoría inmigrantes estadounidenses que se asentaron en Cisjordania y la franja de Gaza, recurrieron a la violencia contra palestinos para mantener el control de los asentamientos que iban ocupando, la mayoría de ellos consideradas colonias ilegales por la legislación israelí, para establecer un estado teocrático basado en la ley religiosa judía o halajá en lo que consideraban el Gran Israel ${ }^{27}$. La visión kanista incluía la construcción de un Tercer Templo en Jerusalén Este, un sueño que requeriría y justificaría la destrucción de las mezquitas del Monte del Templo. El terror instigado por Kach incluyó el incendio de automóviles y autobuses propiedad de palestinos en Jerusalén y Hebrón, matando y mutilando a palestinos que viajaban en autobuses o coches privados a lo largo de las carreteras de Cisjordania, y extendiendo el miedo en los campos de refugiados palestinos cerca de Belén. El acto de terror más notorio asociado con el kanismo fue llevado a cabo el 25 de febrero de 1994 por el Dr. Baruch Goldstein. Este colono, residente en el asentamiento de Kiryat Arba, llegó como todos los días a su lugar de trabajo ataviado con su uniforme de médico de las Fuerzas de Defensa de Israel. Goldstein se desplazó al denominado Muro de Isaac y se dirigió a la conocida como "cueva de los Patriarcas" para los judíos, mezquita de Ibrahim para el islam, donde se encontraban rezando alrededor de 800 musulmanes, la mayor parte de ellos provenientes de Hebrón. Equipado con una ametralladora y una granada de mano asesinó a 29 fieles musulmanes e hirió a 125. Goldstein fue asesinado a golpes por las personas que todavía quedaban en el lugar tras la masacre. Ese atentado fue todo un shock en la sociedad israelí y el propio primer ministro de Israel, Yitzhak Rabin, en una

\footnotetext{
${ }^{27}$ Conviene recordar que desde el punto de vista del Derecho Internacional Público todos los territorios anexionados por Israel tras la guerra de 1967 son ilegales al no ajustarse a la legislación internacional. Al referirme aquí a colonias ilegales estoy haciendo alusión a cómo se las denominada desde el sistema jurídico israelí. Así y desde la legislación israelí, las colonias "legales" serían aquellas aprobadas por el Consejo de Ministros, mientras que las "ilegales" son aquellas en la que los colonos más radicales como los kanistas han establecido pero que no cuentan con el respaldo de la legislación israelí aunque el Estado, al estar todos estos asentamientos en tierras bajo el control de la ANP, les otorga protección militar y servicios básicos hasta que el procedimiento administrativo israelí decrete su evacuación. Según la organización B'Tselem, Centro Israelí de Información sobre los Derechos Humanos en los Territorios Ocupados, se estima que hay unos 547.000 colonos en Cisjordania de los cuales unos 196.000 viven en Jerusalén Este, datos también confirmados por Central Bureau of Statistics de Israel institución homóloga al INE en España. Dicha población estaría repartida en 547 asentamientos de los cuales 98 serían los denominados "ilegales" o Settlement Outpost. Consúltense estos datos en http://www.btselem.org/settlements/statistics (consulta: 23 diciembre 2016).
} 
declaración solemne ${ }^{28}$ en la Knesset, mostró su consternación y desarrolló medidas para la ilegalización del Kach.

Pese a esto, los miembros del kanismo consideraron a Golsdtein como un mártir de la causa sionista. El Consejo de Rabinos de Israel no permitió enterrarlo en un cementerio judío, pero los seguidores del kanismo le dieron sepultura en un aledaño del parque memorial a Meir Kahane en Kiryat Arba, el asentamiento judío adyacente a Hebrón donde vivía Golsdtein. En el lugar se erigió también un mausoleo que se convirtió en lugar de peregrinación de este colectivo. No obstante, esta construcción funeraria fue destruida por las Fuerzas de Defensa Israelíes en diciembre de 1999, tras un fallo del Tribunal Supremo de Israel ${ }^{29}$.

\subsection{Los acuerdos de Oslo y el magnicidio de Rabin}

Como ya sucedió con Camp David, los acuerdos de Oslo firmados en septiembre de 1993 entre Yasser Arafat e Yitzhak Rabin catalizaron la reacción del terrorismo religioso judío, a pesar de que este no había dejado de actuar, aunque de manera menos intensa. Los primeros actos terroristas que se llevaron a cabo los protagonizó un grupo denominado Vengeance Underground, que con su actividad pretendía castigar a los palestinos en respuesta por los ataques que estos habían perpetrado contra colonos judíos, detener la transferencia del territorio de Cisjordania a la recién creada Autoridad Nacional Palestina y atacar a las instituciones ya los líderes políticos de Israel.

El primer atentado terrorista se llevó a cabo muy poco después de la firma de dichos acuerdos, concretamente el 12 de diciembre de 1993, cuando una célula de este grupo estableció un falso control de carretera cerca del pueblo de Hares e

\footnotetext{
${ }^{28}$ Cabe resaltar cómo el Primer Ministro nunca se refiere en el escrito a estos hechos como un acto terrorista sino como asesinato, atrocidad o incidente. Esta declaración titulada "Statement by Prime Minister Rabin on the Murders in Hebron- 25 February 1994" se puede consultar íntegramente en inglés en: Israel Ministry of foreign Affairs. Foreign Policy Historical Documents 1992-1994. 161 Statement by Prime Minister Rabin on the Murders in Hebron- 25 February 1994. Recuperado de http://mfa.gov.il/MFA/ForeignPolicy/MFADocuments/Yearbook9/Pages/161\%20Statement\%20by\%20Pri me\%20Minister\%20Rabin\%20on\%20the\%20Murde.aspx (consulta: 23 diciembre 2016).

${ }^{29}$ Véase el vídeo de esta la destrucción de este mausoleo por las IDF en los archivos de Associated Press (AP) en liguiente ll el http://www.aparchive.com/metadata/youtube/4cfec2c43a9e64f80319417da7a6466e (consulta: 23 diciembre 2016).Sin duda alguna sorprende las declaraciones del padre de Goldstein.
} 
interceptó un coche en el que viajaban tres palestinos y los asesinaron a tiros ${ }^{30}$. Un año más tarde, el Servicio General de Seguridad israelí (Shin Bet), detenía al oficial de las Fuerzas de Defensa Oren Edri, acusado de proporcionarles explosivos y armas. A partir de esta detención se descubrió que los autores eran miembros de Vengeance Underground, y aunque hubo numerosas detenciones de varios colonos del asentamiento Kiryat Arba, el mismo donde había vivido Goldstein, todos fueron acusados solamente de pertenencia a este grupo, no encontrándose a día de hoy a los autores concretos de ese asesinato.

En los meses siguientes estos colectivos de extremistas judíos, tanto de colonos como de ultrareligiosos, fueron aumentando su resistencia a los acuerdos de Oslo. Para ellos ese proceso de paz que se basaba en la premisa de paz y seguridad por territorios, suponía la mayor amenaza para la consecución del Gran Israel y de un Estado religioso judío. En este sentido fueron varios los rabinos que no solo criticaron estos acuerdos, sino que además comenzaron a poner en tela juicio la legitimidad del gobierno de Israel para llevar a cabo los mismos. De esta manera, el movimiento de los colonos comenzó a fijar y a señalar quiénes eran para ellos los culpables. Así, uno de los líderes de este movimiento, Elyakim Haetzni ${ }^{31}$, comparó al gabinete de Rabin con el gobierno de Petain bajo la ocupación nazi; otro de los rabinos del movimiento Gush Emunim, Yoel Bin-Num ${ }^{32}$, negó la legitimidad de Rabin y su gobierno para alcanzar dichos acuerdos. Pero fue a mediados del año 1995 cuando los niveles de presión de la retórica del ultrasionismo religioso subieron enteros, ya que empezaron a aparecer panfletos en distintas sinagogas en las que se llamaba, siguiendo la ley religiosa judía o halajá, al din rodef y al din moser contra Rabin. Ambas figuras,

\footnotetext{
${ }^{30}$ Los asesinados fueron los hermanos Sa'adi y Mahmoud Abdul Mahdi Fatafta de 27 y 25 años respectivamente y su primo Iskhak Mahmoud Fatafta también de 25 años. Los tres jóvenes venían de trabajar en la localidad de Beit Shemesh y se dirigían a sus casas en el pueblo de Tarqumiya. Ninguno de ellos tenían conexión con grupos armados o terroristas palestinos.

${ }^{31}$ Este jurista y líder de los colonos fue también la cabeza visible del partido Tehiya, formación conocida también como la Alianza de los Leales de la Tierra de Israel. Fue miembro del Parlamento israelí en la decimosegunda legislatura, de 1988 a 1992. Tehiya fue una formación ultranacionalista y ultrareligiosa judía fundada en octubre de 1979 bajo la dirección de Geula Cohen. Este partido representó al bloque de Gush Emunim.

${ }^{32}$ Este Rabino imparte clases en el actualidad en la en el Instituto religioso The Herzog Academic College, y en su página se pueden leer sus artículos. http://www.hatanakh.com/en/\%D7\%9E\%D7\%97\%D7\%91\%D7\%A8\%D7\%99\%D7\%9D/rabbi-dr-yoel-binnun (última consulta 28/1172016).
} 
recogidas en la halajá, son sentencias o mesira cuyo castigo es la muerte. La primera, el rodef, es una orden que justificaría el asesinato para salvar la vida de más judíos; la segunda, el moser, permitiría también el atentado contra la vida de aquel que entregue la tierra sagrada a los gentiles ${ }^{33}$.

En este contexto de alta tensión, y con algunos de los sectores ultrareligiosos justificando una acción violenta contra los dirigentes del gobierno de Israel, y muy especialmente contra el primer ministro Rabin, se celebró un acto multitudinario en la plaza de la municipalidad de Tel Aviv. El 4 de noviembre de 1995 la coalición de izquierdas que gobernaba en Israel convocó una manifestación a favor de los acuerdos de Oslo. Este acto consiguió reunir a unas 150.000 personas y supuso, además del apoyo al proceso de paz, la presencia masiva en el espacio público de los partidarios del mismo, rompiendo así una dinámica en la que solo se visualizaba en dicho espacio a los partidarios más radicales del no. Tras finalizar el acto cantando "Shir Lashalom" (Una canción por la paz), la comitiva de Rabin comenzó a abandonar la plaza saludando a los seguidores que todavía estaban allí. Entre ellos apareció Yigal Amir, quien disparó tres veces, alcanzando a Rabin con dos proyectiles expansivos letales, e hiriendo el tercero a uno de sus guardaespaldas. El victimario de este magnicidio fue detenido y resultó ser un activista ortodoxo y ultranacionalista judío, antiguo estudiante de la universidad de Bar Illan.

\subsubsection{Amir como ejemplo del terrorista religioso judío}

El extremista que preparó de manera meticulosa este atentado había rezado antes de cometerlo en la mezquita de Herzliya, un área cercana a la ciudad de Tel Aviv. Yigal Amir era miembro de una familia ortodoxa judía que hizo aliyá ${ }^{34}$ desde Yemen y que tras estudiar en una escuela religiosa, se incorporó a una de las yeshivas más importantes de Israel. Amir hizo sus tres años obligatorios de servicio militar en la brigada Golani, una de las unidades más prestigiosas y mejor preparadas de la infantería israelí, y fue durante esa época donde comenzó a mostrar su fanatismo

\footnotetext{
33 Sobre estas cuestiones consúltese http://dinonline.org/wpcontent/uploads/newsletter/en 68.pdf (consulta: 23 diciembre 2016). Y también, Gideon ARAN y Ron E. HASSNER "Religious Violence in Judaism: Past and Present "Terrorism an Political Violence, Vol 25, pp. 355-405, 2013 _

${ }^{34}$ Este término significa lliteralmente en hebreo ascenso y hace referencia a la "obligación" de todo judío a emigrar a tierra de Israel bajo la Ley de Retorno de julio de 1950. Consúltese esta ley en http://www.knesset.gov.il/laws/special/eng/return.htm (consulta: 23 diciembre 2016).
} 
religioso y su odio tanto a los palestinos como a la izquierda israelí, actitud esta que fue yendo a más durante los dos años que sirvió en Cisjordania. Tras licenciarse del servicio militar fue enviado a Rusia por una organización estatal llamada Nativ ${ }^{35}$, y tras su regreso, ingresó como estudiante en la facultad de Derecho de la Universidad de Bar Illan. En el campus de la única universidad religiosa judía en Israel, Amir se convirtió en uno de los activistas más importantes en contra de los acuerdos de Oslo, que aseguraba ponían en serio peligro la existencia del Estado judío. Al mismo tiempo que criticaba estos acuerdos, lo hizo también con mayor virulencia si cabe contra Rabin.

Tras su etapa en la universidad y ya cada vez más radicalizado, intentó conseguir una autorización rabínica para asesinar a una persona, y más concretamente a otro judío, como era el Primer Ministro; es decir, un din rodef o un din moser. En este sentido, Amir declaró ante la policía que nunca consiguió dichas autorizaciones rabínicas, mientras que algunos rabinos como Yoel Ben-Nun declararon que sí la obtuvo. Pero fue la negativa de algunos rabinos a no aclarar de manera tajante que ni el rodef ni el moser se podían aplicar sobre Rabin lo que reforzó las convicciones de Yigal Amir para llevar a cabo este atentado, y así justificarlo desde sus creencias religiosas. Al mismo tiempo que buscaba una cobertura religiosa para su magnicidio, Amir se fue rodeando de colaboradores, todos ellos pertenecientes a la misma universidad, que le ayudaron a llevar a cabo dicho atentado. Amir fue sentenciado a cadena perpetua mientras que su hermano lo fue a dieciséis años de prisión y el resto de los colaboradores a penas de entre siete años y dieciocho meses.

En cualquiera de los casos el atentado contra Rabin, además del shock que produjo en la sociedad israelí, también fue un punto de inflexión dentro de la historia

\footnotetext{
${ }^{35}$ Esta organización, cuyo nombre real es Lishkat Hakesher, comenzó a funcionar como parte de la oficina del Primer Ministro cuando este cargo lo desempeñó Moshe Sharett en 1952-1953. El Nativ fue diseñado para funcionar secretamente, establecer contactos, fomentar la educación judía y alentar la emigración judía a Israel o aliyá. Pero la actividad de esta agencia fue sobre todo determinante después de la guerra de los Seis Días de junio de 1967, cuando varios países del bloque socialista encabezados por la URSS decidieron romper relaciones diplomáticas con Israel. En ese contexto empezó a desarrollar su actividad en estos países y especialmente en la URSS, aunque de manera clandestina. Pero ese estatus de clandestinidad cambió cuando a mediados de la década de los setenta del siglo pasado, y debido al éxito de la presión internacional sobre la URSS, Moscú empezó a permitir la emigración de la población judía que así lo quisiera a Israel. A partir de este momento la actividad del Nativ, tanto en estos países como en el resto del mundo, es abierta estando a la cabeza de este organismo desde 2005 la antigua embajadora israelí en Kiev, Naomi Ben-Ami. Recuperado de http://www.enativ.com/ (consulta: 23 diciembre 2016).
} 
del terrorismo religioso judío. En primer lugar porque ninguno de los miembros que intervinieron tanto en la preparación como en la ejecución pertenecían a las dos organizaciones religioso-políticas más importantes de Israel, es decir Gush Emunim o el Kahanismo. $Y$ en segundo, porque el terrorismo religioso judío en todos sus actos anteriores siempre había evitado atentar mortalmente contra judío israelíes. En este sentido, los asesinos del Primer Ministro atentaron contra él y contra las instituciones del Estado porque estaban convencidos de que sus actuaciones perjudicaban al pueblo judío de Israel. Esta nueva perspectiva fue adoptada años más tarde por grupos terroristas como Bat Ayin Underground, ya en el contexto de la denominada segunda intifada o de al-Aqsa.

\subsection{De la intifada de Al-Aqsa a la actualidad}

El 29 de septiembre del año 2000 el entonces candidato del Likud al gobierno de Israel, Ariel Sharon, visitó la explanada de las mezquitas de Jerusalén el viernes de oración. Los incidentes que se produjeron a raíz de esa visita dieron comienzo a la segunda intifada, o de al-Aqsa. Con esta visita, y en palabras de Sharon, el candidato quería reivindicar que el Monte del Templo, como así se conoce en la cultura judía ese lugar, era israeli ${ }^{36}$. La segunda intifada sirvió de catalizador para la aparición del Bat Ayin Underground, una red de jóvenes activistas de Cisjordania, religiosamente observantes y muchos de ellos componentes ya de una tercera generación de colonos. Como otros grupos anteriores, este colectivo puso en marcha un conjunto de asentamientos ilegales con la esperanza de sentar sobre los mismos las bases para un Estado teocrático basado en la ley religiosa judía. A comienzos de 2001 comenzaron a perpetrar dos tipos de ataques: disparar a los palestinos al paso de sus automóviles y colocar explosivos en edificios públicos, especialmente en escuelas de aldeas árabes alrededor de Hebrón y de Jerusalén oriental. Varios de sus pretendidos actos terroristas fueron frustrados por los Servicios Generales de Seguridad, y la red se vino abajo después de la detención de sus líderes en 2003.

\footnotetext{
${ }^{36}$ Esta visita recibió amplia cobertura mediática tanto por la prensa israelí como internacional que se puede seguir si se consultan los periódicos del 22 de diciembre de 2000. Por ejemplo Suzanne GOLDENBERG "Rioting as Sharon visits Islam holy site" The Guardian 29/09/2000. Recuperado de https://www.theguardian.com/world/2000/sep/29/israel, o Joel GREENBERG "Sharon Touches a Nerve, and Jerusalem Explodes" New York Times 29/09/2000. Recuperado de http://www.nytimes.com/2000/09/29/world/sharon-touches-a-nerve-and-ierusalem-explodes.html.
}

(Consultas: 23 diciembre 2016). 
La amenaza terrorista de nuevo contra un primer ministro de Israel o contra las instituciones de este país se reactivó cuando a finales de 2003 Sharon puso en marcha el denominado plan de desconexión de Gaza, que suponía el abandono unilateral por parte de Israel de la ocupación de este territorio y de cuatro pequeños asentamientos en el norte de Cisjordania. Tras su definitiva aprobación en octubre de 2004, este plan comenzó a ejecutarse, lo que supuso que las FDI tuvieran que desalojar por la fuerza a varios centenares de colonos radicales judíos. Al igual que tras los acuerdos de Camp David o de Oslo, las opciones más radicales del movimiento de los colonos y de los religiosos se opusieron a dicho plan. En este contexto se produjeron varios intentos de atentados, sobre todo en Tel Aviv, que fueron desbaratados por los servicios de seguridad interior de Israel. El más ambicioso de estos fue el intento de colapsar la autopista de Ayalon mediante un incendio que hiciera que mucha gente se quedara atrapada en el lugar y pereciera. Tras la detención de algunos de estos activistas antes de que llegaran a perpetrar semejante masacre, uno de ellos respondió cuando le preguntaron cuál era su objetivo matando a tanta gente inocente, que no sentía ninguna preocupación porque creían que para la consecución de ciertos objetivos había que cometer atentados en los que personas inocentes podía morir ${ }^{37}$.

Tras el final de la intifada de al-Aqsa, la violencia y terrorismo religioso judío ha seguido existiendo, aunque con una intensidad más baja y con menos víctimas mortales $^{38}$, pero fue en 2015 cuando volvió a cobrarse víctimas mortales, tanto palestinas como judías. El 31 de julio de ese año, varios miembros del movimiento radical sionista conocido como No'ar HaGva'ot ${ }^{39}$ incendiaron dos casas de palestinos

\footnotetext{
${ }^{37}$ Op cit. Pág. 191. Señalar que durante el tiempo que duró la segunda intifada, entre septiembre de 2000 y 2005, se produjeron 43 atentados, perpetrados la mayoría de ellos por miembros Bat Ayin, que se cobraron la vida de veinte personas, todos palestinos o árabe- israelíes. Dato propio extraído a partir del listado de la obra de Ami PEDAHZUR y Arie PERLIGER.

${ }^{38}$ Según la organización $B^{\prime} T$ selem, Centro Israelí de Información sobre los Derechos Humanos en los Territorios Ocupados, entre los años 2000 y 2011 se han contabilizado -es decir, se han denunciado ante la policía israelí- 352 incidentes perpetrados por colonos judíos contra palestinos o contra sus propiedades. De estos, el $71 \%$ de los casos continúan abiertos, el $23 \%$ no fueron investigados y en el $6 \%$ restante no se encontraron a los perpetradores. Léase el informe titulado Settler violence: Lack of accountability: Authorities' handling of complaints regarding settler violence actualizado en enero de 2013 y disponible en http://www.btselem.org/settler violence/law enforcement (consulta: 23 diciembre 2016).

39 Juventud en la cima y en la literatura en inglés Hilltop youth.
} 
en la localidad cisjordana de $D{ }^{40}{ }^{40}$ y escribieron en las paredes consignas en hebreo, incluyendo la palabra "venganza". En una de las casas, el menor de 18 meses Ali Saad Dawabsha murió abrasado mientras que su padre, de 32 años, lo hizo días más tarde y su madre en las semanas posteriores, por lo que tan solo sobrevivió su hermano de cuatro años. En este contexto también hay que mencionar la muerte el 2 de agosto de ese mismo año de la joven israelí de 16 años Shira Banki, como consecuencia de las heridas sufridas por arma blanca cuando participaba en la manifestación del orgullo gay celebrada en Jerusalén. Los hechos sucedieron el 30 de junio de 2015, cuando el activista judío ultraortodoxo Yishai Shlissel apuñaló a seis personas durante esa marcha, actuación casi mimética a la que 10 años antes había perpetrado la misma persona en la misma ciudad y en la misma celebración, y por la que había cumplido una pena de cárcel de diez años. El 26 de junio de 2016 Yishai Shlissel fue condenado a cadena perpetua y a 31 años más adicionales por un tribunal israelí, que al mismo tiempo critico la negligencia de la policía ante este criminal reincidente ${ }^{41}$.

En cuanto a la masacre de Duma, en diciembre de 2015 las autoridades policiales israelíes informaron que habían detenido a siete colonos judíos acusados de participar en ella ${ }^{42}$. Uno de ellos era Meir Ettinger, nieto del fundador del Kach Meir Kahane. Este fue acusado por el Shin Bet de fundar una organización que tenía como objetivo provocar una revuelta violenta para derrocar al Estado de Israel mediante la realización de actos que afectarían a los puntos sensibles del país. En el mismo informe se decía que dicha sublevación se tenía que llevar acabo en cuatro ámbitos diferentes: proselitismo, reclutamiento de activistas, ruptura y levantamiento, y la fase de disturbios ${ }^{43}$. Pero meses más tarde, en junio de 2016, fue puesto en libertad porque

\footnotetext{
40“Muere un niño palestino en un presunto ataque de colonos judíos” bbc Mundo 31/07/2015. Recuperado de http://www.bbc.com/mundo/noticias/2015/07/150730 israel bebe palestino quemado ep (consulta: 23 diciembre 2016).

${ }^{41}$ Consúltese la noticia en "Court convicts Gay Pride Parade stabber Yishai Schlissel of murder" Jerusalem Post 19/04/2016. Recuperado de http://www.jpost.com/lsrael-News/Court-convicts-Gay-PrideParade-stabber-Yishai-Schlissel-of-murder-451678. (consulta: 23 diciembre 2016).

${ }^{42}$ Léase noticia en Juan Carlos SANZ "Israel detiene a judíos sospechosos de quemar viva a una familia palestina" EI PAIS, edición digital. 3/12/2015. Recuperado de http://internacional.elpais.com/internacional/2015/12/03/actualidad/1449139410 703697.html.

${ }^{43}$ Consúltese edición online de HAARETZ, 1/06/2015, http://www.haaretz.com/israel-news/1.722586 (consulta: 23 diciembre 2016).
} 
los mismos servicios de seguridad interior no quisieron extender por más tiempo su detención administrativa. A día de hoy solo está detenido y acusado como perpetrador de dicho atentado, Amiram Ben Uliel ${ }^{44}$, a la espera de juicio definitivo.

\section{El mesianismo político como base intelectual del terrorismo religioso judío}

Es un principio mayoritariamente aceptado en la literatura que aborda este tema, que la base ideológica sobre la que asienta el terrorismo religioso judío es el denominado mesianismo político o sionismo redencionista ${ }^{45}$. Esta expresión ideológica se engloba dentro del fundamentalismo judío $y$, aunque no es un movimiento religioso ultraortodoxo judío o jaredim, sí hunde sus raíces en esta concepción religiosa. A diferencia de la ultraortodoxia judía, el mesianismo político comenzó a adoptar los principios del sionismo tras la Segunda Guerra mundial. Pero sobre todo fue tras la guerra de los Seis Días de junio de 1967 cuando diseñó su ideología en base a un sionismo revisado, y fue en 1974, tras la guerra del Yom Kippur, cuando nació el primer movimiento que definió las líneas ideológicas del sionismo redencionista. Este grupo se llamó Gush Emunim o Bloque de los Fieles, y aunque nunca fue un partido político, sí tomo parte en la política institucional en numerosas ocasiones. Pero lo que sin duda es el hecho más relevante que cabe asociar a este fenómeno es que dotó de ideología política a una parte de la sociedad judía israelí que, al mismo tiempo que creía en la estricta observancia de la ley judía o hajalá, defendía un concepto ultraterritorial del sionismo. Es decir, Emunim unía ortodoxia religiosa judía ${ }^{46}$ y ultranacionalismo judío, así, el sector de la sociedad israelí que comparte esta ideología también es conocida como "nacionalreligiosos".

\footnotetext{
${ }^{44}$ Consúltese en "Amiram Ben Uliel and minor indicted in Duma terror attack" Jerusalem Post 01/03/2016. Recuperado de http://www.jpost.com/Israel-News/Duma-indictments-expected-today439195 (consulta: 23 diciembre 2016).

${ }^{45}$ Idith ZERTAL y Akiva ELDAR Lords of the Land: The War Over Israel's Settlements in the Occupied Territories, 1967-2007. 2009 o Motti INBARI. Messianic Religious Zionism Confronts Israeli Territorial Compromises. Cambridge, Cambridge University Press, 2012.

${ }^{46}$ La diferencia entre las concepciones religiosas judías ortodoxa y ultraortodoxa estribaría en que la primera aboga por un marco estatal moderno (nacional-religioso) donde la halajá, código de leyes de la religión judía, sea la ley prevalente y fundamental, mientras que la segunda rehúye de los principios sionistas, sobre todo los referidos a la estatalidad, dado que esta forma de organización de las sociedades no tiene base bíblica y es producto de la modernidad.
} 
El primero de los aspectos que caracterizan al mesianismo político es el concepto de "redención". El nexo común mayoritario de las personas que se identifican con esta ideología es que han estudiado en las denominadas yeshivas o colegios talmúdicos, que en términos rabínicos dependían del que fue el primer rabino jefe de Israel, Yitzhak Ha-Cohen Kook. Este rabino pensaba que la era de la redención del pueblo judío había comenzado con el nacimiento del sionismo. La afirmación fue reinterpretada por sus discípulos tras la guerra de los Seis Días, pensando que con la obtención por parte de las tropas israelíes de Jerusalén Este la redención a la que Kook se refería había comenzado. Además, esta interpretación fue defendida en aquellos años por el hijo del propio Kook, Yehuda, quien como líder espiritual de este movimiento definió al Estado de Israel como el reino de la halajá, es decir, el reino del cielo en la tierra. Para los participantes del mesianismo político esto significaba que ya se encontraban en la era de la reconstrucción de Tercer Templo, y por tanto la tierra estaría "redimida" cuando no estuviera poblada por gentiles (no judíos). De ahí su manera de referirse a la ocupación con población judía de los territorios de Cisjordania -para ellos Judea y Samaria- como "redimir la tierra".

Otro elemento que caracteriza a este sionismo redencionista es el carácter celestial que otorgan a la tierra de Israel. Dicho de otra manera, para el mesianismo político Eretz-Israel era y es la tierra santa. En este sentido hay que subrayar que el concepto territorial que sobre las dimensiones de dicha "tierra santa" tiene este movimiento desbordan las dimensiones del actual Estado de Israel y de los territorios bajo el control de la ANP de Gaza y Cisjordania. Acorde con sus referencias bíblicas, la tierra del pueblo judío sería la que Dios entregó a Abraham, lo que en términos geográficos se traduciría en lo que se denomina al gran Eretz-Israel que lindaría al suroeste con el Nilo y al noroeste con el Éufrates ${ }^{47}$. Por lo tanto, los partidarios del mesianismo político o sionismo redencionista están en contra no solo de que Gaza y Cisjordania estén en manos palestinas, sino que también se oponen a la devolución del Sinaí a Egipto y de los altos del Golán a Siria. De esta manera, y en coherencia con sus creencias redencionistas y sus concepciones territorialistas de base bíblica, son partidarios de una acción masiva de construcción de asentamientos por todo lo que

\footnotetext{
47 "A tu descendencia daré esta tierra, desde el río de Egipto hasta el río grande, el Éufrates". Génesis 15:18.3.
} 
ellos consideran como la tierra del Gran Israel. Asimismo, para los partidarios del sionismo redencionista la vanguardia del "nuevo sionismo" es recuperar el espíritu de los pioneros en la consecución de la tierra "sagrada" de Israel. Por esa razón reivindican un "nuevo sionismo de vanguardia" que crea en el sentido bíblico de la acción de ocupar la tierra de Israel solo con población judía.

La influencia del mesianismo político en el discurso israelí llega hasta la actualidad al haber calado sobre todo su concepción ultraterritorialista en el debate político. En este sentido cabe resaltar que gran parte del discurso de la derecha, y sobre todo de la ultraderecha sionista, tanto religiosa como no religiosa, asume o ve con buenos ojos las ambiciones territoriales del sionismo redencionista, bien sea por convicciones religioso-históricas o por cuestiones relativas a la seguridad de Israel. En la actualidad son las organizaciones Yesha Council y Amana ${ }^{48}$ las que representan gran parte del corpus ideológico de esta corriente. A nivel político sería el ala más conservadora del Likud pero sobre todo la formación Habayit Hayehudit ${ }^{49}$ de Naftali Bennett, actual Ministro de Educación del gabinete Netanyahu, el máximo exponente de esta ideología.

\subsection{La respuesta del estado de Israel ante el terrorismo judío}

En cuanto al papel del Estado a la hora de afrontar el fenómeno del terrorismo judío, ya desde el incidente del Altalena las instituciones de Israel dieron prueba del vigor del Estado de derecho en este país ${ }^{50}$. Pero al mismo tiempo no han faltado voces que han alertado sobre todo a partir de los años noventa del siglo pasado del creciente problema que suponía el terrorismo religioso judíi ${ }^{51}$. En este sentido, acusaban a los

\footnotetext{
48 Sobre estos grupos consúltese sus web: http://theyeshacouncil.org/ y http://www.amana.co.il/?CategorylD=101\&ArticlelD=166 (consulta: 23 diciembre 2016).

${ }^{49}$ Consúltese la web de esta formación política en http://www.habayithayehudi.com/ (consulta: 23 diciembre 2016).

${ }^{50}$ Nombre del barco que transportaba armas para el Irgun, milicia liderada por Begin, y que ante la negativa de sus tripulantes a cederlas al gobierno provisional de Israel presidido por Ben Gurion, fue atacado por el propio Thazal (Fuerzas de Defensa de Israel) el 21 de junio de 1948. Esta actuación del ejército regular israelí provocó la muerte de 17 milicianos del Irgun y 3 militares de las FDI. Finalmente fue en septiembre de 1948 y tras un ultimátum del gobierno provisional, cuando esta milicia se incorporó al ejército de Israel.

${ }^{51}$ Dentro de la sociedad civil israelí una de las organizaciones que ha denunciado esta deriva con más insistencia esta la ACRI, The Association for Civil Rights in Israel. Sitio web http://www.acri.org.il/en/ (consulta: 23 diciembre 2016).
} 
distintos gobiernos israelíes de no emplear la misma intensidad en la lucha contra este fenómeno como lo hacían contra el terrorismo árabe. La respuesta de la administración siempre ha sido que la actuación era proporcional a la envergadura de la amenaza y de los actos cometidos por uno y otro terrorismo.

Pero fue sin duda el magnicidio contra Rabin el que volvió a recuperar este debate ya que en algunos círculos sociales israelíes se acusó sobre todo a los gobiernos del país de ser condescendientes con este tipo de expresiones violentas y de terrorismo, que en muchas ocasiones estaba ligado al movimiento de los colonos que, a su vez, en sus distintas expresiones políticas en la Knesset, sustentaban a los distintos gobiernos de Israel. Estos mismos sectores han relacionado también el desarrollo de este fenómeno terrorista con la creciente influencia de la religión judía en la sociedad y en el Estado de Israel. Más allá de este debate, lo que sí se puede afirmar es que a partir de los atentados del verano de 2015 el gobierno de Netanyahu reconoció que había terrorismo judío, y según afirmó "sería tratado igual que el palestino" ${ }^{52}$. En este sentido cabe resaltar que uno de los instrumentos principales con el que cuenta el actual gobierno de Israel son las denominadas detenciones administrativas, es decir detenciones preventivas sin orden judicial y sin límite de tiempo, que han sido y son habitualmente utilizadas contra los sospechosos palestinos y ahora contra los judíos ${ }^{53}$. Al mismo tiempo, a los considerados como posibles terroristas judíos se les podrá aplicar la técnica policial del tiltul ${ }^{54}$, denominación en hebreo que hace referencia a la posibilidad por parte de las fuerzas de seguridad israelíes de "utilizar un grado de violencia aceptable" en los interrogatorios, "técnica" esta que fue ya limitada por la Corte Suprema de Israel en 1996 y que ha sido considerada por muchas asociaciones de derechos humanos como la legalización de

\footnotetext{
52 Esta noticia fue ampliamente cubierta por medios israelíes como internacionales. "Netanyahu reconoce que hay "terrorismo judío" y dice que no lo aceptará" 25/12/2015 Agencia Efe. Recuperado de http://www.efe.com/efe/espana/portada/netanyahu-reconoce-que-hay-terrorismo-judio-y-dice-no-loaceptara/10010-2796623 (consulta: 23 diciembre 2016).

${ }^{53}$ Para más información sobre esta figura administrativa léase B'Tselem - The Israeli Information Center for Human Rights in the Occupied Territories. Recuperado de http://www.btselem.org/administrative detention (consulta: 23 diciembre 2016).

${ }^{54}$ tiltul (sacudir), consiste en sostener al detenido por el cuello de su camisa y sacudirlo violentamente. Recuperado de https://www.wcl.american.edu/hrbrief/v4i3/israel43.htm. También sobre esta técnica en B'Tselem The Israeli Information Center for Human Rights in the Occupied Territories. Recuperado de http://www.btselem.org/search/google cse adv/tiltul (consultas: 23 diciembre 2016).
} 
la tortura en el Estado e Israel ${ }^{55}$. También hay que destacar que en junio de 2016 el parlamento aprobaba una nueva ley antiterrorista que, entre otras cosas, tipifica como delito el ser autor intelectual de un acto terrorista ${ }^{56}$. Además, las organizaciones que apoyan a grupos terroristas pueden ser declaradas ilegales y sus miembros enviados a prisión por asociación ilegal.

\section{Conclusiones: una somera radiografía del terrorismo religioso judío}

Lo primero que hay señalar respecto al terrorismo religioso judío es que en lo referente a la cronología de oleadas de terrorismo (González Calleja 2013), este fenómeno no se ajustaría a dicho marco cronológico, constituyendo así una singularidad. Esto es debido a que el terrorismo religioso judío no nació a finales del siglo $\mathrm{XX}$, sino que lo hizo a mediados de esa centuria. Este fenómeno terrorista coincidiría en cronología con la tercera oleada que apunta González Calleja, pero con la quinta en lo que hace referencia a su naturaleza religiosa. Una segunda característica que cabe resaltar es que nunca ha sido un fenómeno de escala global o internacional, ya que tanto sus actuaciones como sus objetivos han estado circunscritos a Israel.

Así, el terrorismo religioso judío reivindica mayoritariamente tanto el carácter sagrado de la tierra bíblica de Israel, Eretz-Israel, como el principio de la "redención", o del "retorno" del pueblo judío a la tierra sagrada para la construcción del Tercer Templo. Es decir, este fenómeno englobaría en sí mismo dos elementos fundamentales: un principio de territorialidad, el Gran Israel, emanado y definido en los textos religiosos, y un modelo de sociedad y de Estado teocrático fundamentado en la ley judía o hajalá. Ambos elementos, ultranacionalismo judío y ortodoxia religiosa, coincidirían con las propuestas políticas del mesianismo político o sionismo

\footnotetext{
55 Sobre esta sentencia léase https://www.wcl.american.edu/hrbrief/v4i3/israel43.htm (consulta: 23 diciembre 2016).

${ }^{56} \mathrm{Si}$ bien es cierto que esta legislación es un avance más, fueron sobre todo los parlamentarios árabeisraelíes los que votaron en contra de esta ley ya que entendían que estaba diseñada para aplicársela solamente a ellos, ya que tipifica también como acto terrorista el cavar túneles si se prueba que tienen un objetivo logístico para un acto terrorista. Véase la ley en https://www.knesset.gov.il/spokesman/eng/PR eng.asp?PRID=12118 (consulta: 23 diciembre 2016).
} 
redencionista. Cabe mencionar también que en algunos casos, los menos, como el del ultraortodoxo Yishai Shlissel, sería exclusivamente el componente religioso el que explicaría y "justificaría" su acción violenta ${ }^{57}$.

Y es bajo esta premisa ideológica sobre la que este fenómeno ha perpetrado sus actos de terror contra la población árabe o contra la población judía. A su vez, y desde una perspectiva histórica, los objetivos de este terrorismo aparecido en Israel desde su fundación en 1948 han perseguido un doble objetivo. Primero, "evitar" lo que ellos han entendido como un proceso de secularización creciente de la sociedad israelí, consecuencia a su vez del modelo de Estado laico que preconizaba el sionismo clásico, que rechazaba la teocracia de ley religiosa judía como modo de organización del país. El segundo objetivo ha sido el de boicotear e impedir cualquier iniciativa de paz con los palestinos o con el resto de los países árabes, ya que al basarse estos acuerdos en la premisa de paz por territorios, aquellos dirigentes israelíes que asumieran ese principio "traicionarían" la concepción bíblica territorial del Gran Israel que ellos defienden. Tal y como apuntó el sociólogo de la Universidad Hebrea de Jerusalén, Shlomo Fischer, en una entrevista en el New York Times en referencia a uno de los detenidos por el atentado de Duma, Meir Ettinger (nieto de Meir Kahane), estos activistas son representantes de grupos violentos que se perciben a sí mismos como poseedores de "algún tipo de carisma y autoridad profética" y que "no aceptan la validez de las leyes israelíes ni la validez de la moralidad cívica" ${ }^{58}$.

Otra de las características que han definido a este fenómeno, es que ninguno de los grupos que se englobarían dentro del terrorismo religioso judío han contado nunca con una estructura lo suficientemente asentada que les permitiera su pervivencia en el

\footnotetext{
${ }^{57}$ Hay una parte minoritaria pero reseñable de la ultraortodoxia judía que no es partidaria del sionismo al ser esta una ideología laica. Este sería el caso de Yishai Shlissel. Si bien es cierto que este antisionismo no les lleva a actuar contra el Estado de Israel, siempre y cuando respete su modo de vida. Un ejemplo de este tipo de colectivos lo encontraríamos en el barrio ultraortodoxo de Mea Shearim en Jerusalén. En el extremo de la ultraortodoxia religiosa judía antisionista estarían los miembros de Naturei Karta (en arameo, guardianes de la ciudad). En su búsqueda activa de la destrucción del Estado de Israel apoyaron en su momento a los gobiernos de Ahmadineyad en Irán ya que su objetivo era destruir la "entidad sionista", como denominaba a Israel. Además, son partidarios de la no existencia del Estado de Israel y del surgimiento en su lugar de un Estado palestino donde entienden que se respetarían sus creencias religiosas. El líder de este movimiento es el rabino Moshe Hirsch.
}

58 Léase el reportaje en New York Times de 4/08/2015 http://www.nytimes.com/2015/08/05/world/middleeast/israel-palestinians-meirettinger.html? $r=0$ (consulta: 23 diciembre 2016). 
tiempo. Tal y como señalan Pedahzur y Perliger (2011), el fenómeno terrorista religioso judío ha adolecido de una falta casi total de los elementos básicos que han definido los modelos organizativos de otros terrorismos clásicos, tales como estructuras claras de mando, jerarquía, mecanismos de actuación regulados y estrategia de cara a una actuación en el escenario público en la reivindicación de sus atentados. Esto, a su vez, se explicaría por el propio proceso de gestación de estos grupos, cuyo origen y componentes han pertenecido principalmente a ámbitos de sociabilidad muy determinados, como son las colonias. Un ejemplo claro de esta realidad es que muchos de los componentes del kanismo pertenecían a la colonia de Kiryat Arba, o incluso eran familiares en tercera generación de su fundador Meir Kahane. Es decir, hasta la actualidad, ninguno de estos grupos ha conseguido establecer una organización que vaya más allá de sus espacios más cercanos de sociabilidad o incluso de sus ámbitos familiares. Por tanto, es sobre todo en el ámbito de los asentamientos, en algunos de los cuales la militancia en el mesianismo político es prácticamente unánime, donde estos grupos han encontrado las fuentes de su creación, pero también los límites de su pervivencia. Para sociólogos como Baruch Kimmerling bien se pueden ubicar estos fenómenos terroristas en ámbitos de una subcultura política o en algunos casos incluso en una contracultura ${ }^{59}$.

Además de las colonias han sido algunas yeshivas los espacios de sociabilidad de los cuales han salido algunos de los victimarios, como es el caso de los componentes Brit Hakanaim o de Yishai Shlissel, todos ellos ultraortodoxos judíos. Y es en este último ejemplo en el que se puede establecer una cierta analogía con el fenómeno de los denominados "lobos solitarios" ${ }^{60}$. Es decir, aquellas personas que en el marco de un discurso determinado -en este caso religioso ultraortodoxo judío, en otros el del islam más rigorista- deciden perpetrar un atentado. Individuos como Shlissel no pertenecen a ningún grupo terrorista ni responden ante ninguna jerarquía que les ordene cometer atentados como el de Jerusalén, sino que es su propio

\footnotetext{
${ }^{59}$ Baruch KIMMERLING. The Invention and Decline of Israeliness. State, Society, and the Military. S. Mark Taper Foundation Book in Jewish Studies, 2005.

${ }^{60}$ En ámbitos policiales a este fenómeno se le prefiere denominar como "los inspirados", es decir aquellos "...que consumen la propaganda y, pese a no recibir ninguna instrucción o indicación, pueden dar el paso en cualquier momento de atentar" Léase EL PAIS 11/3/2017, recuperado de http://politica.elpais.com/politica/2017/03/10/actualidad/1489180255 324931.html (consulta: 11 de marzo 2017).
} 
fanatismo religioso adquirido en ámbitos muy determinados el que les empuja a ello. Además, dichos activistas reciben la comprensión y el reconocimiento de sus comunidades por los actos violentos que han perpetrado. Es por tanto el discurso del mesianismo político redencionista y/o el de la ultraortodoxia religiosa judía más rigorista el que dotaría a estos fanáticos religiosos de la cobertura intelectual para sus actuaciones violentas. Y es ahí donde estos actos también se pueden enmarcar dentro del fenómeno terrorista religioso judío.

En cuanto a los procesos de radicalización de victimarios como Shlissel o Goldstein, o en general los relacionados con el terrorismo religioso judío, estos, a día de hoy y a diferencia de los denominados lobos solitarios ligados al terrorismo yihadista, no están vinculados mayoritariamente a las redes sociales. Cabe resaltar además que en las comunidades ultraortodoxas judías el acceso a internet es limitado y sus contenidos están controlados en todo momento por los rabinos de dichas comunidades. En el caso del terrorismo religioso judío es el propio entorno familiar y social ya radicalizado el que simplemente les educa en esa misma dirección, y el que les dota de una radicalidad que en un momento determinado puede desembocar en actuaciones violentas. En este sentido se puede hablar de una radicalidad heredada, como bien se puede ver en al caso de Ettinger, miembro ya de una tercera generación de kanistas.

Pero las redes terroristas judías también comparten similitudes con otros grupos terroristas religiosos, como los yihadistas o fundamentalistas cristianos en los Estados Unidos $^{61}$. Todas estas comunidades se adhieren a ideologías que combinan componentes religiosos, territoriales y nacionalistas. Además, sus militantes perpetran los actos violentos como la única vía redentora para crear un nuevo orden. Los miembros de tales grupos tienden a justificar el terror como un deber divino ordenado por una interpretación radical de las escrituras religiosas. Estos grupos fundamentalistas religiosos que practican la violencia política, rechazan la reconciliación y tienden a reclutar miembros de redes familiares y de amistad que a menudo están integrados en instituciones religiosas y culturales.

\footnotetext{
${ }^{61}$ Sobre este tipo de terrorismo y la historia del fenómeno en sí es léase Eduardo GONZÁLEZ CALLEJA: El laboratorio del miedo: una historia general del terrorismo: de los sicarios a Al Qa'ida. Barcelona, Crítica 2013.
} 
Para finalizar, no se debe olvidar que el terrorismo religioso judío se da en un escenario político y social, como el israelí, donde los movimientos de colonos, tanto los representados en la Knesset como en el gobierno, han servido y sirven de gran armazón ideológico para estas actuaciones, aunque oficialmente no las compartan y solo las condenen cuando la víctima es un judío, como en el caso del asesinato de Rabin o de la joven Shira Banki. También se desarrolla en aquellos ámbitos donde el Estado tiene cada vez más dificultades para mantener los espacios de laicidad del mismo. Por lo tanto, bien se puede afirmar que, intelectualmente, las bases para la reaparición, desarrollo y perpetuación de terrorismo religioso judío en Israel tienen solidas estructuras mientras persistan grupos como Gush Emunim o Yesha Council en activo, o partidos como Habiyat Hayeudin (Hogar Judío) incluso en el gobierno. Todas estas organizaciones, junto con algunos rabinos minoritarios, arman el discurso tanto político como religioso para este tipo de actividades. En este sentido, y aunque en los últimos tiempos el gobierno de Netanyahu ha empezado a tomar conciencia de lo extremadamente grave que puede llegar a ser este fenómeno, es de esperar que la intensidad de la lucha del Estado de Israel contra el terrorismo religioso judío sea comparable a la que desarrolla contra el palestino, como así demanda una parte muy importante de la población judía israelí, y aseveró el propio Primer Ministro. 